Ensino

\title{
Interfaces entre a Política Nacional de Proteção e Defesa Civil e a Política Nacional de Educação Ambiental
}

\author{
Interfaces between the National Policy of Civil Protection and Defense \\ and the National Policy of Environmental Education
}

\section{Amanda Regina Coutinho da Silva'(1), Masato Kobiyama"1(1), Franciele Maria Vanelli"ID}

\author{
' Universidade Federal de Santa Catarina, Florianópolis, SC, Brasil \\ "Universidade Federal do Rio Grande do Sul, Porto Alegre, RS, Brasil
}

\section{RESUMO}

As políticas públicas refletem as propostas do Governo para solucionar problemas públicos. A sinergia entre distintas políticas públicas pode viabilizar a efetividade das soluções. Portanto, existem grandes desafios para o estabelecimento de interfaces entre as políticas públicas. Assim, este trabalho objetivou analisar a Política Nacional de Proteção e Defesa Civil (PNPDEC) e a Política Nacional de Educação Ambiental (PNEA) e propor diretrizes para sua integração. Os resultados desse estudo demonstram que a PNPDEC e a PNEA apresentam alto potencial de sinergia e de integração. Portanto, para efetivar ambas as políticas públicas, sugere-se a criação de programas definidores de metodologias e mecanismos para a gestão de riscos e de desastres na educação formal e não formal de forma permanente. Sugere-se que a integração entre os diversos atores sociais que compõem a sociedade contribui para ampliar o conhecimento sobre prevenção, mitigação, e preparação para desastres, bem como noções de desenvolvimento sustentável. Portanto, a consolidação dessas duas políticas públicas pode viabilizar a responsabilidade compartilhada entre o poder público e os cidadãos.

Palavras-chave: Prevenção; Desastres; Políticas Públicas

\section{ABSTRACT}

Public policies reflect government proposals to solve public problems. The synergy between different public policies can make the solutions effective. Therefore, there are major challenges to the establishment of interfaces between public policies. Thus, this work aimed to analyze the National Policy of Protection and Civil Defense (PNPDEC) and the National Policy of Environmental Education (PNEA) and propose guidelines for its integration. The results of this study demonstrate that PNPDEC and PNEA have high potential for synergy and integration. Therefore, to implement both public policies, it is suggested the creation of methodological programs and mechanisms for risk and disaster management in formal 
and non-formal education on a permanent basis. It is suggested that integration among the various social actors that make up society contributes to broadening knowledge about prevention, mitigation, and disaster preparedness, as well as notions of sustainable development. Therefore, the consolidation of these two public policies can make possible the shared responsibility between the public authorities and the citizens.

Keywords: Prevention; Disaster; Public policies

\section{INTRODUÇÃO}

A falta de preparo dos países atingidos por desastres em anos anteriores a década de 1990 motivou a Organização das Nações Unidas (ONU) a desenvolver um conjunto de estratégias para incentivar o aprimoramento da gestão de riscos e de desastres. A Década Internacional para a Redução de Desastres Naturais, 1990 - 1999 evidenciou uma atitude de otimismo e de convicção em prol dos recursos técnicos e científicos disponíveis para enfrentar esta ameaça global, mediante uma ação internacional em comum (RODRIGUES, 2010; TRAJBER et al., 2017). A Declaração de Hyogo e o Marco de Ação 2005-2015 foram adotados por 168 países na Conferência Mundial sobre Redução de Desastres, em Kobe no Japão, no ano de 2005, colocando como prioridade aos países e às comunidades locais a construção da resiliência aos desastres, na busca pela redução do risco (CUTTER, 2011; RODRIGUES, 2010).

Cutter (2011) definiu a resiliência como a habilidade de uma comunidade para se preparar, planejar, absorver, recuperar-se e adaptar-se com mais sucesso a eventos adversos reais ou potenciais. A resiliência compõe-se de diversos elementos que adotados de forma integrada e participativa são aptos a reduzir os impactos de desastres. Wisner, Gaillard e Kelman (2011) prelecionam que a compreensão dos riscos e vulnerabilidades, permeados pela incerteza, possui relação com o acesso aos recursos naturais sobre os quais se constrói a subsistência. O acesso aos recursos é distribuído de forma desigual, assim como o acesso aos locais de residência seguros, à infraestrutura que permite mobilidade, comunicação e marketing, exposição espacial e temporal a perigos naturais e meios de proteção. Desta forma, os autores concluem que as pessoas não são igualmente capazes de 
acessar recursos nem estão igualmente expostas aos perigos. Neste sentido, a depender do contexto social, características como sexo, idade, estado de saúde física e mental, ocupação, estado civil, sexualidade, raça, etnia, religião e status de imigração podem ter influência na perda potencial, lesão ou morte em face dos perigos - ou recursos transformados em perigos - e as perspectivas e processos para mudar essa situação (WISNER, GAILLARD E KELMAN, 2011).

A redução das diversas vulnerabilidades existentes para redução de riscos é imprescindível, ao passo que Marchezini, Muñoz e Trajber (2017) destacam a vulnerabilidade educacional, relacionada ao presente estudo, definindo-a como o grau de fragilidade das comunidades escolares (estudantes, professores, alunos, funcionários, moradores do entorno, bens tangíveis e intangíveis da escola) em função do contexto ambiental onde se encontram inseridas, dos tipos de ameaças às quais estão expostas, e da somatória de outras vulnerabilidades que afetam as escolas e a sociedade como um todo. Na busca por uma maior integração entre governo e populações locais, o Marco de Ação de Hyogo abordou a necessidade de promover o desenvolvimento sustentável e a redução dos riscos de desastres (ALMEIDA, 2015). Ressalte-se que o governo possui papel relevante no processo de promoção do desenvolvimento sustentável e da redução de riscos, diante da necessidade de concretização dos objetivos assumidos na esfera internacional. Por sua vez, a criação de políticas públicas é imprescindível para que os compromissos assumidos sejam, de fato, institucionalizados.

Para Sachs (2015) o desenvolvimento sustentável é um modo de compreender o mundo como uma interação complexa de sistemas econômicos, sociais, ambientais e políticos. O autor entende como sendo uma visão ética e normativa do mundo, uma maneira de definir os objetivos de uma sociedade próspera economicamente, socialmente inclusiva, ambientalmente sustentável e bem governada. A falta destes elementos na formação da sociedade, a exemplo da urbanização rápida e não planejada sem uso racional dos recursos naturais, é responsável por desencadear os riscos de desastres vivenciados. 
Wisner, Gaillard e Kelman (2011) afirmam que o risco de desastre se relaciona com a magnitude, ocorrência potencial, frequência, velocidade de início e extensão espacial de um evento ou processo natural potencialmente prejudicial. Também se refere à suscetibilidade das pessoas à perda, lesão ou morte. Neste contexto, algumas pessoas estão em melhor posição para se recuperar rapidamente dessas perdas do que outras. Em conjunto, a suscetibilidade a danos e o processo que a cria e a mantém podem ser chamados de "vulnerabilidade". A vulnerabilidade, por sua vez, pode ser contrabalançada pela capacidade individual e local de ação protetora ou por ações de proteção realizadas por entidades maiores, como o governo (WISNER, GAILLARD E KELMAN, 2011).

Com o avanço do Marco de Ação de Hyogo e com as lições trazidas pela tragédia do tsunami que ocorreu em Fukushima no Japão em 2011, o Marco de Sendai estabeleceu as seguintes metas e objetivos: (i) prevenir novos riscos e reduzir o risco de desastres existente; (ii) implantar medidas econômicas, estruturais, jurídicas, sociais, de saúde, culturais, educacionais, ambientais, tecnológicas, políticas e institucionais integradas e inclusivas que previnam e reduzam a exposição a perigos e a vulnerabilidade a desastres; (iii) aumentar a preparação para resposta e recuperação; e (iv) aumentar a resiliência (UNISDR, 2015).

Wisner, Gaillard e Kelman (2011) apontam que diante dos 168 governos que assinaram o Marco de Ação de Hyogo em 2005, seria de se esperar que houvesse continuidade do trabalho. No entanto, percebe-se que as ações governamentais na construção da cultura de redução de risco de desastres (RRD) são precárias no que se refere ao uso e conservação da terra, da água e da biosfera, não contribuindo ao desenvolvimento sustentável e aumentando os riscos aos desastres.

Apesar disso, notam-se iniciativas de treinamento e pesquisa científica sobre perigos e risco de desastres, na busca por uma melhor integração com outras áreas do planejamento, dentre elas, a educação ambiental e o desenvolvimento 
sustentável. No que se refere à educação, destaca-se a Iniciativa Mundial para Escolas Seguras (Worldwide Initiative for Safe Schools - WISS) da United Nations Office for Disaster Risk Reduction- UNDRR. Por meio desta, escolas, agências e governos se comprometem a promover a segurança escolar globalmente com enfoque na segurança de infraestrutura, preparação e inclusão de redução de riscos de desastres nos currículos escolares (UNIDRR, 2019). Assim, incentiva-se a cultura da prevenção, ao invés do enfoque tradicional na resposta aos desastres. No âmbito da WISS da UNISDR, o objeto dessa pesquisa se insere no eixo "educação para resiliência a desastres". Este eixo busca ensinar sobre os perigos naturais e sobre os riscos, fornecendo conhecimentos, habilidades e atitudes para apoiar ações de proteção da comunidade antes, durante e depois do desastre (AIDR, 2019).

No contexto brasileiro, a Lei Federal n 12.608 promulgada em 2012 instituiu a Política Nacional de Proteção e Defesa Civil (PNPDEC) (BRASIL, 2012). Esta lei dispõe sobre a necessidade de integração dos entes federativos e da sociedade civil no enfrentamento dos desastres naturais. Busca abranger ações de prevenção, mitigação, preparação, resposta e recuperação. Em harmonia com o cenário internacional, foi conferida especial atenção à etapa de prevenção pela integração com as políticas de meio ambiente e educação.

De acordo com Birkland (2016), as políticas públicas expressam como os governos de cada país encaram os problemas coletivos e planejam soluções. A PNPDEC inovou ao prever o repasse de recursos da União para os Municípios para a execução de ações de prevenção, através de alteração da Lei $n^{\circ} 12.340$ promulgada em $1^{\circ}$ de dezembro de 2010 (BRASIL, 2010). Buscou-se o estímulo ao desenvolvimento de medidas de prevenção de desastres e recuperação de áreas afetadas (BACK, 2016).

Percebe-se que uma política nacional de forma isolada pode funcionar efetivamente sob certos aspectos, uma vez que se verificam trabalhos destinados a promover a resiliência de comunidades expostas aos riscos de desastres por meio da educação, além de medidas estruturais buscando a prevenção de riscos. 
Ocorre que estas ações nem sempre são eficientes para solucionar os riscos socioambientais que crescem nas áreas vulneráveis em decorrência do planejamento urbano deficiente, ausência de programas de realocação de famílias para áreas seguras, dentre outros. O repasse de recursos aos Municípios para fazer frente a estes desafios enfrenta obstáculos de natureza política e institucional. Neste sentido que a integração de várias políticas públicas representa medida de especial valor. Conforme Venderuscolo e Kobiyama (2007), as ações da Defesa Civil permanecerão voltadas às medidas de resposta e recuperação se não houver esforço conjunto de diversas políticas. Com essa visão, no Brasil, Venderuscolo e Kobiyama (2007) relacionaram a Política Nacional de Recursos Hídricos (PNRH) e a Política Nacional de Defesa Civil com relação aos desastres hidrológicos. Em suas conclusões, apontaram que o diálogo entre estruturas descentralizadas possui grande potencial para o desenvolvimento de estratégias. Exemplificaram a aproximação entre o Comitê de Bacia e o Núcleo Comunitário de Defesa Civil (NUDEC) para construção da cultura de prevenção. Além disso, a importância da participação ativa das comunidades para consolidação e efetividade das medidas de mitigação, prevenção e preparação aos desastres.

Facchetti et al. (2017) relacionaram a PNPDEC à Política de Saneamento e demonstraram que a prevenção da ocorrência de desastres somente acontecerá quando a política de planejamento urbano estiver integrada com as demais políticas. Incluíram neste rol as políticas de saneamento ambiental, de recursos hídricos e de defesa civil, além da efetiva participação popular, de modo a exercer o controle social. Dulac e Kobiyama (2017) analisaram a PNPDEC, a PNRH e a Lei de Diretrizes Nacionais para Saneamento Básico. Avaliaram as interfaces entre elas com relação às medidas para redução dos riscos de desastres, constatando que mesmo que os objetivos das políticas sejam comuns, as estratégias para alcançálos não são integradas.

Com base nisso, indaga-se como as políticas públicas podem concretizar estratégias de prevenção de desastres naturais voltadas para educação. Como 
mencionado, a tendência mundial na redução de desastres é a forte consideração com outras esferas de planejamento, dentre elas a inserção da educação na gestão de riscos e de desastres. A educação é um componente considerado cada vez mais importante no contexto mundial de redução de desastres (MANYENA, 2006; MUTTARAK e LUTZ, 2014; WEICHSELGARTNER e PIGEON, 2015; MÖNTERA e OTTO, 2018).

No Brasil, em 1999, foi instituída a Política Nacional de Educação Ambiental (PNEA) pela Lei nº 9.795 (BRASIL, 1999). Devido à necessidade de preservação ambiental para sustentabilidade global e local, a educação ambiental vem ganhando seu espaço no Brasil (SORRENTINO et al., 2005; FURTADO, 2009; RIBAS et al., 2016), o que levou a implementação da PNEA.

Barbieri e Silva (2011) expõem que durante a Conferência das Nações Unidas para o Meio Ambiente Humano, realizada em Estocolmo, em 1972, foram criados alguns instrumentos para tratar de problemas sociais e ambientais planetários, como a Declaração sobre o Ambiente Humano, com 26 princípios voltados para orientar a construção de um ambiente que harmonizasse os aspectos humanos e naturais, considerados essenciais para o bem-estar dos seres humanos e que possibilitasse o gozo de todos os direitos fundamentais. O princípio 19 ressalta que um trabalho de educação em questões ambientais direcionado para jovens e adultos é indispensável. A Conferência de Estocolmo firmou as bases para um novo entendimento acerca das relações entre o ambiente e o desenvolvimento socioeconômico.

O marco inicial da institucionalização da EA brasileira foi a Lei $n^{\circ}$ 6.938/81, que estabeleceu a Política Nacional de Meio Ambiente (PNMA). A Lei citada referese à EA em todos os níveis de ensino, inclusive a educação da comunidade para a defesa do meio ambiente.

Devido ao próprio termo técnico empregado, as interfaces entre educação ambiental e meio ambiente vêm sendo discutidas amplamente por diversos pesquisadores, como Barbosa (2008) e Novicki e Souza (2010). Além disso, Saito 
(2011) tratou a relação entre educação ambiental e recursos hídricos, mas não mencionou as políticas nacionais. Assim, é necessário discutir a educação ambiental e a redução de desastres naturais, de modo a analisar as políticas públicas que permeiam tais conceitos. Isso possibilita avaliar como as políticas públicas do Brasil possibilitam a execução de estratégias de prevenção de desastres naturais voltadas para educação em proteção e defesa civil. Marchezini, Muñoz e Trajber (2017) discutiram a vulnerabilidade escolar frente a desastres no Brasil ressaltando que a construção de escolas inseguras (vulnerabilidade estrutural) em áreas sujeitas a inundações, deslizamentos, terremotos maximiza os riscos da comunidade escolar.

Portanto, o objetivo do presente trabalho, com base em estudo documental, foi analisar a PNPDEC e a PNEA e propor diretrizes para sua integração. A metodologia adotada foi (i) a caracterização das duas políticas sob suas abordagens quanto à prevenção e abrangência social, (ii) a análise comparativa de ambas as políticas públicas para identificar relações de similaridade, através dos critérios de repartição de competências vislumbrando o ensino da proteção e defesa civil, além da busca pela participação da sociedade, e (iii) a identificação das diretrizes para integração efetiva entre essas políticas.

\section{A ESTRUTURA DA POLÍTICA NACIONAL DE PROTEÇÃO E DEFESA}

\section{CIVIL}

A Constituição Federal de 1988 previu como competência privativa da União legislar sobre defesa civil. Além disso, previu no art. 21, inciso XVIII, a competência da União para planejar e promover a defesa permanente contra as calamidades públicas, especialmente as secas e as inundações. Posteriormente, diversas leis ordinárias regulamentaram este artigo, entre elas as de $n^{\circ}$ 9.433/1997, $11.445 / 2007$ e 12.608/2012. No entanto, ainda, não foram suficientes para deter o número crescente de vítimas desses desastres (FACCHETTI et al., 2017). 
Back (2016) e Facchetti et al. (2017) apontaram que a PNPDEC contemplou inovações no ordenamento jurídico brasileiro buscando a integração com as demais políticas, dentre as quais, as políticas de ordenamento territorial, meio ambiente e educação. Como forma de contribuir para a execução dos objetivos da PNPDEC foi estabelecido o Sistema Nacional de Proteção e Defesa Civil (SINPDEC) para atuar no processo de planejamento, articulação, coordenação e execução dos programas, projetos e ações de proteção e defesa civil. Saleme e Bonavides (2018) informam que este sistema agrupa não somente entes da administração pública federal, estadual e municipal, mas também entidades privadas de atuação marcante na defesa civil. Criou-se o Conselho Nacional de Proteção e Defesa Civil (CNPDEC) para acompanhar o cumprimento das disposições legais e regulamentares da proteção e da defesa civil. Autorizou a criação do sistema de monitoramento e informações de desastres e, ainda, definiu competências e estabeleceu diretrizes a serem alcançadas pelo Poder Público e sociedade civil.

As três esferas do governo foram incumbidas de adotar medidas para redução de risco de desastres e de conferir a possibilidade de colaboração de entidades públicas e privadas. Conferiu destaque para medidas com vistas à promoção da integração com as demais políticas públicas e a prioridade para ações de prevenção, no ambiente escolar, de responsabilidade do Poder Público e da sociedade.

Em relação à competência comum, a União definiu que Estados e Municípios deveriam desenvolver a cultura nacional de prevenção de desastres, com foco para o desenvolvimento da consciência nacional acerca dos riscos de desastre. Incumbiu à União, aos Estados e aos Municípios o estímulo a comportamentos de prevenção capazes de evitar ou minimizar a ocorrência de desastres. Ressaltou a importância de medidas preventivas de segurança contra desastres em escolas e hospitais situados em áreas de risco.

As ações de prevenção podem ser subdivididas em medidas estruturais e não estruturais. O objeto deste estudo se refere à educação, medida não estrutural, 
que vislumbra uma perspectiva de longo prazo diferentemente das medidas estruturais que são tópicas e datadas.

É imperioso que as ações executadas pelo poder público e a sociedade civil nos momentos anteriores ao desastre sejam efetivas, a fim de garantir melhores resultados e minimizar custos. Em contraposição, ações de resposta e reconstrução em inúmeros casos ultrapassam os limites orçamentários do próprio ente federativo, necessitando de ajuda internacional. Um fato é que medidas preventivas (ou ações na fase de prevenção e mitigação) são mais eficientes na gestão de riscos e de desastres (GRD). Entretanto, historicamente, tanto no Brasil quanto em outros países, a criação de mecanismos de GRD esteve associada à ocorrência de grandes desastres concentrando-se, essencialmente, no período do evento e pós-evento (ALMEIDA, 2015).

Apesar disso, conforme Dulac e Kobiyama (2017), tem sido promovida uma cultura de prevenção, baseada no conhecimento dos riscos, nas ações prospectivas e corretivas para redução e preparação para o manejo dos desastres. Assim, um dos desafios da PNPDEC se refere à própria natureza do desastre. A ocorrência de um desastre não é completamente previsível e, portanto, pode não ser total e facilmente gerenciável (ALMEIDA, 2015). Além disso, os limites políticos não impõem barreiras ao desastre. Desse modo, é necessário articulação e cooperação intermunicipal e interestadual a fim de que seja possível fornecer uma resposta eficiente à população afetada (ALMEIDA, 2015). Independente desses fatores, a promoção da educação para resiliência deve ser desenvolvida permanentemente e prioritariamente, em conjunto com princípios de proteção, defesa civil e meio ambiente conforme pretendido pela PNPDEC. A PNPDEC deve incentivar o ensino e a pesquisa sob um enfoque transdisciplinar. Desta forma será possível a tomada de decisões coletivas pensadas para os contextos locais das comunidades, o que pode vir a ser a diferença entre vida e morte (FACCHETTI et al., 2017). Assim, por determinação legal, a educação para resiliência terá de incluir as atribuições dos atores sociais de todas as políticas públicas existentes em uma única metodologia 
na busca de uma GRD efetiva. O que caracteriza um desafio para o contexto brasileiro.

Neste sentido, foi publicado o Decreto $\mathrm{n}^{\circ} 10.593$ de 24 de dezembro de 2020 (BRASIL, 2020) o qual determinou a elaboração do Plano Nacional de Proteção e Defesa Civil no prazo de 30 meses, a contar de sua publicação. Este mencionou, ainda, que os planos estaduais, distritais e municipais deveriam ser elaborados em articulação com o disposto no Plano Nacional definindo princípios, objetivos e metas integrados e coordenados. Dessa forma, espera-se que o conflito de competências entre União, Estados e Municípios no momento da aplicação de suas atribuições em casos concretos ocorra com o devido planejamento.

Percebe-se um esforço de modificação das estratégias de GRD para ações de prevenção. Verifica-se que a PNPDEC no artigo $5^{\circ}$, inciso XIV enumera como objetivo: "orientar as comunidades a adotar comportamentos adequados de prevenção e de resposta e promover a autoproteção". O Decreto n 10.593/2020 prevê que o Plano deverá fortalecer a cultura de resiliência.

Dentre as ações previstas pela PNPDEC, foi introduzido o parágrafo $7^{\circ}$ no artigo 26, da Lei Federal n 9.394/1996 que estabelece as Diretrizes e Bases da Educação Nacional. Ele previa a obrigatoriedade de o ensino de proteção e defesa civil no nível fundamental e médio e a educação ambiental serem integrados aos conteúdos obrigatórios (BRASIL, 1996). No entanto, o dispositivo foi revogado pela Lei Federal n 13.415 (BRASIL, 2017), alterando o parágrafo que passou a disciplinar: "A integralização curricular poderá incluir, a critério dos sistemas de ensino, projetos e pesquisas envolvendo os temas transversais de que trata o caput.".

O caput do artigo 26 da Lei 9.394/1996 prevê:

Os currículos da educação infantil, do ensino fundamental e do ensino médio devem ter base nacional comum, a ser complementada, em cada sistema de ensino, e em cada estabelecimento escolar, por uma parte diversificada, exigida pelas características regionais e locais da sociedade, da cultura, da economia e dos educandos. 
Neste sentido, entende-se que a PNPDEC em um primeiro momento determinou a obrigatoriedade do ensino de proteção e defesa civil em escolas de nível básico. Após, com a alteração foi conferida transversalidade ao ensino escolar, cabendo a adequação das estruturas curriculares, além das disciplinas comuns, incluírem temas complementares. Percebe-se que tais matérias poderiam incluir assuntos de interesse de comunidades em áreas de risco. Anteriormente, a lei tratava de forma expressa da obrigatoriedade do ensino de proteção e defesa civil. Tal menção foi suprimida cabendo ao jurisdicionado interpretar a aplicação de princípios de proteção e defesa civil. A facultatividade conferida ao assunto na educação formal somada as demais alterações trazidas pela Lei reduzem o grau de importância de diversos dispositivos os quais passam a depender dos escassos recursos disponíveis.

Hernandes (2017) informa que a Lei $n^{\circ} 13.415$ (BRASIL, 2017) estabeleceu nova composição para o currículo: parte deve ser destinada à Base Nacional Comum Curricular (BNCC), no máximo 1.800 horas para sua integralização, e a outra parte para itinerários formativos, com cinco arranjos curriculares. A intenção foi flexibilizar parte do currículo do Ensino Médio com caminhos formativos à escolha dos estudantes, dependendo das possibilidades de oferta dos sistemas de Ensino.

A Lei $n^{\circ} 13.415$ (BRASIL, 2017), promulgada em fevereiro de 2017, por ter iniciado seu trâmite pela Medida Provisória 746, editada em setembro de 2016, não permitiu um maior debate sobre as alterações propostas para o Ensino Médio pela sociedade brasileira, pela comunidade educativa, tampouco, permitiu que os sistemas de Ensino fizessem diagnósticos sobre as possibilidades de sua realização na realidade concreta das escolas públicas e privadas. 


\section{A ESTRUTURA DA POLÍTICA NACIONAL DE EDUCAÇÃO AMBIENTAL}

A Educação Ambiental surgiu da necessidade de uma mudança de paradigma que envolve valores sociais, filosóficos, econômicos, éticos, ideológicos e científicos, adotados pela nossa sociedade. Dessa forma, a escola é corresponsável pela promoção dessas mudanças, juntamente com o poder público por meio da legislação na área ambiental (BRANCO, ROYER e BRANCO, 2018).

A Educação Ambiental (EA) foi elevada a nível constitucional no artigo 225 da Constituição Federal de 1988, que preceitua: todos têm direito ao meio ambiente ecologicamente equilibrado, bem de uso comum do povo e essencial à sadia qualidade de vida, impondo-se ao Poder Público e à coletividade o dever de defendê-lo e preservá-lo para as presentes e futuras gerações.

Assim, no ano de 1999 foi sancionada a Lei Federal n. 9.795, que dispõe sobre a EA e institui a Política Nacional de Educação Ambiental (PNEA). Define a EA como os processos por meio dos quais o indivíduo e a coletividade constroem valores sociais, conhecimentos, habilidades, atitudes e competências voltadas para a conservação do meio ambiente (AZEVEDO et al., 2017).

A responsabilidade pela execução da PNEA fica a cargo de um órgão gestor incumbido de definir diretrizes para sua implementação em âmbito nacional. Este órgão deve promover a articulação de planos, programas e projetos participando nas negociações de financiamento.

Segundo Da-Silva-Rosa et al. (2015), desde a década de 1980, o Brasil teve leis que procuraram colaborar para o fortalecimento da educação ambiental. Os autores corroborados por Viana et al. (2016) asseveram, porém, que ocorreram mudanças somente com o advento da PNEA. Atribuíram-se responsabilidades aos órgãos e entidades do SISNAMA pela criação de programas, além das instituições públicas e privadas de ensino e ONGs.

Azevedo et al. (2017) entendem a EA como um direito do cidadão e que é matéria de suma importância para o desenvolvimento da sociedade brasileira. 
Encontra-se afigurada sua importância na necessidade de se compreender a função local e regional das escolas enquanto agentes propulsores de mudanças, objetivando a sustentabilidade.

A PNEA previu que a EA deve ocorrer no ensino formal e não formal com quatro linhas de atuação: (i) formação de educadores e demais profissionais e sua atualização quanto aos temas sobre meio ambiente; (ii) desenvolvimento de estudos, pesquisas e experimentações a fim de implementar a educação ambiental em todos os níveis e modalidades de ensino; (iii) produção e divulgação de material educativo; e (iv) acompanhamento e avaliação. Barbosa (2008) afirma que aprender a prevenir e enfrentar as ameaças em uma sociedade de risco implica na criação de espaços de interlocução para novas formas de participação política e vivência da vida democrática.

Na PNEA, a redução de desastres naturais e a educação para resiliência não são mencionados. Apesar disso, há uma abordagem integrada e composta de relações que envolvem aspectos ecológicos, psicológicos, legais, políticos e sociais. Azevedo et al. (2017) ressaltam que a PNEA fornece um roteiro para a prática da EA, constituindo-se verdadeira ferramenta para o despertar da consciência ecológica. O paradigma do desenvolvimento sustentável tem, na instância educativa, uma grande aliada.

Em 2012, ocorreu no Brasil a Rio+20, momento em que foi discutida e lançada a Rede Planetária de Educação Ambiental, como parte da implantação do Tratado de EA. Nesse mesmo ano, o Brasil aprovou as Diretrizes Curriculares Nacionais de Educação Ambiental (DCNEA) considerado uma referência, uma vez que reafirmou o papel da EA, sua obrigatoriedade em todos os níveis e modalidades de ensino, dispondo sobre os seus princípios e objetivos, além de tratar sobre a organização curricular e os sistemas de ensino e colaboração.

Ainda, em 2012, houve a inserção da EA como conteúdo obrigatório na Lei de Diretrizes e Bases da Educação Nacional (LDBEN). Verifica-se assim que a EA, até esse momento, evoluía numa perspectiva crescente, uma vez que ao longo do 
tempo sua inserção em documentos oficiais foi ampliada e vários programas foram criados visando sua implantação no país (OLIVEIRA e ROYER, 2019).

Diante do exposto, caberia inferir que o ensino sobre as estruturas sociais e sua ação no meio ambiente poderia ser um caminho de aplicação da EA voltada para prevenção de desastres naturais. A partir deste ponto, a EA passa a assumir posição estratégica na prevenção de desastres naturais envolvendo atores sociais com interesses múltiplos na preservação ambiental futura.

Conforme Layrargues (2009), a PNEA assegura a universalização do acesso à EA, devendo estar presente em todos os espaços educativos possíveis. A PNEA traz uma abordagem educacional complementar com outras relações sociais, a concepção do meio ambiente em sua totalidade, considerando a interdependência entre o meio natural, o socioeconômico e o cultural. Essa abordagem se dá com ênfase na sustentabilidade e de forma articulada com as questões ambientais locais, regionais, nacionais e globais.

De acordo com Branco, Royer e Branco (2018), a Base Nacional Comum Curricular, em sua última versão suprimiu a educação ambiental no ensino formal como componente curricular, incorporando aos currículos e propostas pedagógicas a abordagem de "temas contemporâneos" preferencialmente de forma "transversal e integradora". Percebe-se a preferência pela utilização de termos indeterminados, de interpretação aberta, o que pode contribuir para descontextualizar toda a abordagem que era trazida por normatizações anteriores, enfraquecendo a própria PNEA. Isso faz com que a Educação Ambiental (EA) tenha dificuldade em se consolidar no espaço escolar brasileiro, o que reflete em práticas fragmentadas, pontuais e desconexas em relação aos conteúdos específicos e a realidade, conforme anotam Oliveira e Royer (2019).

Ressalte-se que a própria Resolução 02/2012 (BRASIL, 2012) que estabeleceu as Diretrizes e Bases da Educação Ambiental previu como objetivo a adoção de uma abordagem que considerasse a interface entre a natureza, a sociocultura, a produção, o trabalho, o consumo, superando a visão despolitizada, acrítica, 
ingênua e naturalista ainda muito presente na prática pedagógica das instituições de ensino. Observa-se, contudo, que esta visão não foi mantida pela BNCC, fragilizando referida matéria.

\section{INTERFACES ENTRE A POLÍTICA NACIONAL DE PROTEÇÃO E DEFESA CIVIL E A POLÍTICA NACIONAL DE EDUCAÇÃO AMBIENTAL}

A análise comparativa entre as duas políticas públicas (PNPDEC e PNEA) possibilita apontar as medidas preventivas como objetivos comuns. A PNPDEC, almejando o desenvolvimento sustentável, buscou a integração com outras políticas, dentre elas, as de educação e meio ambiente. A PNEA, de forma mais específica, voltou-se à perspectiva educacional. Essa política atribuiu às instituições educativas a promoção da EA de maneira integrada e permanente aos programas educacionais.

Com esta atribuição, a PNEA previu aquilo que posteriormente foi tratado pela Lei $n^{\circ} 13.415 / 2017$ que incluiu o artigo 26, parágrafo $7^{\circ}$ da Lei de Diretrizes e Bases da Educação. Definiu-se que a integralização curricular poderia incluir projetos e pesquisas envolvendo, além da base nacional comum, temas transversais. Como temas transversais, definiu abordagens relacionadas às características regionais e locais da sociedade, da cultura e da economia dos educandos. Esse aspecto demonstra o interesse pela promoção da EA integrada às demais áreas em nível local, podendo incluir nesta seara, a educação para proteção e defesa civil.

A PNPDEC ainda incumbiu à União, aos Estados e aos Municípios a adoção de medidas preventivas de segurança contra desastres em escolas e hospitais situados em áreas de risco. Em consonância, a PNEA determinou ao Poder Público a promoção da EA em todos os níveis de ensino, o que possibilitaria a integração com a redução de riscos de desastres. 
A PNPDEC, ao determinar a promoção de ações preventivas em escolas situadas em áreas de risco, além de buscar abranger medidas de infraestrutura e educação para resiliência, também almejou a autoproteção. Similarmente, a PNEA buscou atribuir a toda a sociedade, individual e coletivamente, atenção permanente voltada para a prevenção, identificação e solução de problemas ambientais.

No campo de atuação da EA se encontram questões relacionadas à sustentabilidade que tangenciam questões relacionadas à proteção e defesa civil. Segundo Vieira et al. (2017), a EA constitui um dos instrumentos da GRD como processo contínuo, permanente e transversal. Essas relações se tornam possíveis ao se estabelecerem interfaces entre a PNPDEC e a PNEA, possibilitando a aplicabilidade do ensino de proteção e defesa civil em todos os níveis de ensino. 0 diálogo entre EA e prevenção de desastres naturais pode contribuir para os cidadãos compreenderem os fenômenos naturais e se tornarem participativos na GRD. Conforme Sulaiman e Jacobi (2013), a integração entre esses dois aspectos desenvolve um comportamento de "questionamento" do risco, sendo capaz inclusive de aprimorar a preparação e resposta em situações de emergência. DaSilva-Rosa et al. (2015) afirmam que no contexto da redução de riscos de desastres, é crucial se buscar compreender o modo pelo qual a sociedade interage com a natureza, porque as interações estabelecidas são fundamentais para a sobrevivência dos seres humanos,

A UNESCO (2012) corroborada por Petal e Izadkhah (2008) propõe que a redução do risco de desastres deve ser sistemática e lentamente difundida no currículo. Realizando-se uma auditoria no currículo existente e projetando pontos de entrada em seu transcurso se poderão atingir todos os sujeitos e faixas etárias. Isso deve ocorrer não apenas na ciência básica de riscos e medidas de segurança, como também na construção da prevenção, mitigação, vulnerabilidade e resiliência. Portanto, a EA vai além de conteúdos pedagógicos, posto que ela interage com o 
ser humano e articula os saberes entre as disciplinas, mudando atitudes, hábitos e culturas.

Apesar de as interações entre a educação ambiental e a educação voltada para a proteção e defesa civil ainda serem recentes, considerando que a PNPDEC é datada de 2012, observam-se trabalhos nesta perspectiva, bem como várias ações educativas de modo a promover a cultura de redução de riscos em comunidades. Patrício et al. (2011) propõem a implementação de programas de educação ambiental como o Programa de Gestão de Resíduos Gerados no Instituto Federal da Paraíba - IFPB - Campus João Pessoa com vistas ao desenvolvimento da gestão ambiental em nível institucional. Pesquisas desenvolvidas por Uchôa (2013) e por Leonardi (2018) de modo a avaliar o “Programa Brigada Escolar: A Defesa Civil na Escola" do Governo do Estado do Paraná apontaram a necessidade de se promover uma cultura de prevenção e enfrentamento de desastres. Este Programa possui uma relação próxima com as medidas de preparação para incêndios.

Além desses exemplos, Kobiyama et al (2009) desenvolveram o curso "Aprender Hidrologia para prevenção de desastres naturais" como projeto de extensão através de palestras e minicursos desenvolvidos pela Universidade Federal de Santa Catarina junto à comunidade. Neto (2017) analisou o "Programa Minas Gerais Mais Resiliente" criado em 2016 por meio do Gabinete Militar do Governador de Minas Gerais e concluiu que medidas como a integração de diversos setores da sociedade e treinamento da população para promover práticas de prevenção e proteção contribuem para o incremento na capacidade de resiliência local. No que se refere à educação ambiental, existe o Programa Nacional de Educação Ambiental coordenado pelo órgão gestor da Política Nacional de Educação Ambiental, buscando alcançar grupos em condições de vulnerabilidade social e ambiental, gestores, técnicos, docentes e estudantes de todos os níveis e modalidades de ensino, dentre outros (MMA, 2018). O Projeto "Defesa Civil na Escola" da Defesa Civil do Município de Blumenau/SC ocorre desde 2013, sendo analisado por diversos autores, dentre os quais, pode-se citar: Ribeiro, Vieira e Tômio (2017), Vieira, Müller e Marchi (2017) e Oliveira, Ouriques e Correia 
(2018) que buscaram analisar a percepção de risco de alunos. Os referidos autores constataram o êxito nas ações de prevenção, de modo a tornar os alunos capazes de adotar ações e comportamentos de prevenção e resiliência.

Como a PNPDEC é datada de 2012, grande parte das ações desenvolvidas em anos anteriores ocorria tendo como escopo apenas uma área do conhecimento. Isso é perceptível no que se refere aos estudos acima mencionados os quais buscam trabalhar junto ao público-alvo apenas uma área do conhecimento sem integrá-la às demais. Não obstante, observam-se nos anos seguintes ações com o objetivo de promover maior integração com a educação ambiental. Silveira e Panceri (2018) desenvolveram a partir de 2012, um programa em nível estadual, intitulado "Programa Defesa Civil na Escola" o qual tem como público-alvo alunos de escolas públicas municipais no Estado de Santa Catarina com o intuito de fomentar a cultura de prevenção de riscos de desastres e, conjuntamente, a conscientização ambiental.

Para analisar a interface entre PNPDEC e PNEA é necessário compreender os princípios da PNEA, que podem ser estendidos à PNPDEC. Os três princípios da PNEA são: (i) o pluralismo de ideias e concepções pedagógicas, na perspectiva da inter, multi e transdisciplinaridade, relacionando a necessidade de articulação da PNEA com as demais políticas sociais e de desenvolvimento econômico; (nesse caso, cabe para a PNPDEC); (ii) a concepção do meio ambiente em sua totalidade, considerando a interdependência entre o meio natural, o socioeconômico e o cultural, sob o enfoque da sustentabilidade levantando a questão de que é imprescindível a interação entre educação ambiental e sociedade com o meio ambiente para o estabelecimento de inter-relações harmônicas; e (iii) a abordagem articulada das questões ambientais locais, regionais, nacionais e globais a fim de se pensar no contexto social em que a educação deve se inserir adequando-se às especificidades de cada grupo.

Com base no exposto, a Tabela 1 apresenta a interface entre a PNPDEC e a PNEA. Nota-se que, em atenção às medidas preventivas, a PNPDEC prioriza a prevenção através do planejamento adequado, aliado ao aumento da capacidade 
das pessoas. Assim, propõe o combate às ocupações em áreas ambientalmente vulneráveis com realocação das comunidades. Estimula, ainda, a autoproteção somada ao monitoramento e alerta antecipados. Enquanto isso, a PNEA ressalta a necessidade de educação ambiental no ensino formal e não formal de forma permanente sob um enfoque integrado.

Tabela 1 - Interface entre Política Nacional de Proteção e Defesa Civil (PNPDEC) e Política Nacional de Educação Ambiental (PNEA)

\begin{tabular}{ccc}
\hline ABORDAGEM & PNPDEC & PNEA \\
\hline Integração & $\begin{array}{c}\text { Integração de políticas públicas, incluindo-se as } \\
\text { de ordenamento territorial, desenvolvimento } \\
\text { urbano, meio ambiente, educação, ciência e } \\
\text { tecnologia tendo em vista a promoção do } \\
\text { desenvolvimento sustentável. }\end{array}$ & $\begin{array}{c}\text { educação ambiental de maneira integrada aos } \\
\text { programas educacionais que desenvolvem. }\end{array}$ \\
$\begin{array}{c}\text { O desenvolvimento de uma compreensão integrada } \\
\text { do meio ambiente em suas múltiplas e complexas } \\
\text { relações, envolvendo aspectos ecológicos, } \\
\text { psicológicos, legais, políticos, sociais, econômicos, } \\
\text { científicos, culturais e éticos. }\end{array}$
\end{tabular}

Competência dos entes

Alcance desejado na sociedade

Noção de desenvolvimento sustentável

Estimular o desenvolvimento de cidades resilientes e os processos sustentáveis de urbanização; redução do risco de desastre.

Orientação das comunidades a adotar autoproteção.
Incumbência da União, Estados e Municípios na comportamentos adequados de prevenção e de resposta em situação de desastre e promover a

A prioridade às ações preventivas relacionadas à minimização de desastres. À União apoiar a comunidade docente no desenvolvimento de material
Incumbência do Poder Público em promover a EA em todos os níveis de ensino.

Incumbe à toda sociedade, manter atenção permanente à formação de valores, atitudes e habilidades que propiciem a atuação individual e coletiva voltada para a prevenção, a identificação e a solução de problemas ambientais.

Concepção do meio ambiente em sua totalidade, considerando a interdependência entre o meio natural, o socioeconômico e o cultural, sob o enfoque da sustentabilidade;

Abrangência da EA no ensino formal e não formal. 


\section{DIRETRIZES PARA INTEGRAÇÃO ENTRE A POLÍTICA NACIONAL DE PROTEÇÃO E DEFESA CIVIL E A POLÍTICA NACIONAL DE EDUCAÇÃO AMBIENTAL}

Ao analisar as interfaces entre a PNPDEC e a PNEA se observam aproximações entre os objetivos com a finalidade de promover a educação ambiental integrada à proteção e defesa civil no ensino formal e não formal. A preocupação com o desenvolvimento sustentável é elemento que se destaca em ambas as políticas. A atribuição de responsabilidades alcança a União, os Estados e os Municípios para que adotem medidas de proteção e defesa civil e educação ambiental.

Além disso, ambas se preocupam em conferir à sociedade responsabilidades em nível local por meio da autoproteção e auto-organização, o que de acordo com Da-Silva-Rosa et al. (2015), é característica das normas ambientais a inclusão da necessidade de participação da coletividade para a defesa e melhoria da qualidade ambiental. Apesar de demonstrada a existência de similaridades entre as duas políticas públicas, as inter-relações entre elas carecem de operacionalização na perspectiva de planos, programas e projetos a serem executados nas esferas locais e regionais (Tabela 2 ). 
Tabela 2 - Proposta de Diretrizes para Integração entre Política Nacional de Proteção e Defesa Civil (PNPDEC) e Política Nacional de Educação Ambiental (PNEA)

\begin{tabular}{|c|c|}
\hline DIRETRIZES & PNPDEC/PNEA \\
\hline Integração & $\begin{array}{l}\text { Incentivar mecanismos e desenvolvimento de metodologias para } \\
\text { integração da PNEA x PNPDEC }\end{array}$ \\
\hline Contrapartidas & $\begin{array}{l}\text { Estímulo ao desenvolvimento de estratégias para concretizar os objetivos } \\
\text { previstos nas políticas com a criação de contrapartidas e sanções em } \\
\text { casos de descumprimento. }\end{array}$ \\
\hline Competência dos entes & $\begin{array}{l}\text { Mensurar a capacidade de fazer dos entes públicos no contexto da } \\
\text { gestão dos riscos e dos desastres naturais }\end{array}$ \\
\hline Alcance desejado na & Realizar programas de EA orientados para gestão de riscos e de \\
\hline sociedade & desastres naturais com foco na autoproteção \\
\hline $\begin{array}{l}\text { Noção de desenvolvimento } \\
\text { sustentável }\end{array}$ & $\begin{array}{c}\text { Adotar os objetivos do desenvolvimento sustentável propostos pela ONU } \\
\text { e orientá-los para a gestão de riscos e desastres naturais. }\end{array}$ \\
\hline Educação & $\begin{array}{l}\text { Desenvolver programas interministeriais de EA integrada pra gestão de } \\
\text { riscos e de desastres naturais, na educação formal e não formal. }\end{array}$ \\
\hline
\end{tabular}

Fonte: Autores (2021)

Layrargues (2009) questionou se as atribuições conferidas à União, aos Estados e aos Municípios na forma prevista pela PNEA teriam um caráter vinculativo. Criticou a dubiedade na interpretação dos artigos, que poderiam ter um caráter genérico, quase a título sugestivo. Esta margem de interpretação deixada pela Lei poderia levar à percepção de que estes entes teriam permissão para o não cumprimento das medidas ali previstas, renunciando as suas responsabilidades. Caberia trazer esta reflexão também para a PNPDEC ao passo que em nenhum momento foram previstos mecanismos de sanção em casos de descumprimento das medidas previstas. Portanto, as políticas públicas carecem de instrumentos para compelir os entes públicos a executar o que está determinado. Apesar disso, os cenários de desastres naturais necessitam de ações por parte do Poder Público no que se refere à adoção de medidas preventivas, 
apresentando-se como estratégia de integração entre as políticas, as seguintes diretrizes: (i) criação de programas que estabeleçam metodologias e mecanismos de integração da GRD na educação formal e não formal de forma permanente. Tais programas devem atingir as mais variadas searas sociais de modo a se tornarem efetivas; (ii) criação de mecanismos de sanção em casos de não aplicação dos objetivos previstos nas políticas públicas, fixando prazos para seu cumprimento; (iii) fixação de contrapartidas para aqueles que desenvolverem estratégias de redução de riscos de desastres; (iv) realização de análise institucional dos entes públicos a fim de possibilitar a mensuração de suas capacidades, direcionando-as para a GRD. Isso orientará as instituições e, consequentemente o país, para uma gestão integrada de redução de riscos de desastres; e (v) somado a isto, a educação para GRD deve incorporar noções de sustentabilidade para melhoria do meio ambiente, na busca dos objetivos do desenvolvimento sustentável, conforme pretendido pela PNPDEC e pela PNEA.

Os Objetivos de Desenvolvimento Sustentável representam uma agenda mundial adotada pela Organização das Nações Unidas para o alcance de metas até 2030 em benefício da coletividade. Compõe-se de 17 objetivos e dentre eles, encontra-se a promoção de educação de qualidade, paz, justiça e instituições fortes bem como parcerias em busca de metas (ONU, 2020). Com base nisso, aponta-se que sua aplicação na gestão de riscos e de desastres pode trazer reflexos positivos para a coletividade.

A situação de risco socioambiental a que estão submetidas as populações excluídas pelo modelo de desenvolvimento tardio, como no caso brasileiro, é um problema ambiental ainda enfrentado de forma desarticulada, no país como um todo, tanto pelo poder municipal como pela sociedade em geral (DA-SILVA-ROSA et al. 2015). Os autores afirmam que apesar da incerteza do desastre, é indicado que as ações de mitigação almejem a sustentabilidade do desenvolvimento como é proposto em debates internacionais sobre redução de riscos de desastres. Neste sentido, o que se observa é a possibilidade de coordenação de propósitos entre os 
debates das mudanças climáticas, da sustentabilidade e da redução de riscos de desastres posterior a Hyogo, complexificando o cenário futuro da RRD na medida em que outros atores sociais poderão dele participar.

Weichselgartner e Pigeon (2015) apontaram que na França, após a tempestade Xynthia e as inundações da área de Var (fevereiro e junho de 2010, respectivamente), foi proposto um acordo de parceria público-privada com uma plataforma para coleta de dados de risco e compartilhamento entre partes interessadas e regiões. Em maio de 2012, isso levou interessados a criar o Observatório Nacional de Riscos Naturais (ONRN). O portal do ONRN fornece acesso aos dados disponibilizados por mais de 100 instituições, por exemplo, em relação às políticas de exposição, perdas e prevenção, principalmente, na escala municipal (WEICHSELGARTNER E PIGEON, 2015). Tais ações possibilitam que as comunidades tomem maior conhecimento dos acontecimentos que podem provocar riscos a fim de se tornarem mais resilientes, conforme pretendido pela PNPDEC.

Evidencia-se que apesar de a PNPDEC e a PNEA estabelecerem a integração com demais áreas de planejamento (por exemplo, DULAC e KOBIYAMA, 2017), as instituições públicas e privadas e a própria sociedade necessitam instrumentalizar formas de estabelecer estas relações de modo concreto. A contribuição de todos os atores envolvidos no processo educativo, cujo engajamento é imprescindível, pode proporcionar uma nova abordagem da educação ambiental direcionada ao enfrentamento dos riscos de desastres (DA-SILVA-ROSA et al., 2015). A criação de conselhos participativos e audiências públicas podem aproximar as instituições públicas e privadas das necessidades de cada comunidade e seu contexto social para execução de projetos. Isso facilitará a criação de estratégias adequadas compreendendo os princípios de proteção e defesa civil e EA a fim de promover a resiliência das comunidades expostas a riscos de desastres. 


\section{CONSIDERAÇÕES FINAIS}

A PNPDEC possui objetivos amplos, conferindo diversas competências aos mais variados atores sociais. Apesar disso, os diversos atores sociais responsáveis por efetivar as medidas previstas encontram dificuldades diante da necessidade de envolvimento de variados setores. Dentre os objetivos, encontra-se a educação a qual necessita de metodologias a fim de que as pretensões da PNPDEC se interrelacionem com os objetivos da PNEA.

No entanto, no corpo da PNEA não foi incluído dentre seus objetivos, a redução de desastres naturais ou a educação para resiliência a desastres. Apesar disso, a educação é composta de uma série de objetivos integradores aos contextos sociais e ambientais, dentre eles, o ensino voltado à forma como a sociedade se organiza e influencia o meio ambiente. Neste sentido, o modo como se formam os aglomerados urbanos e seus impactos são um caminho a ser seguido para a EA coordenada visando a prevenção de desastres naturais.

Em âmbito nacional, houve a recente promulgação do Decreto 10.593/2020 que conferiu prazo para elaboração do Plano Nacional de Proteção e Defesa Civil.

Independente disso, as estruturas nacionais, regionais e locais de proteção e defesa civil precisaram se organizar para responder as necessidades sociais cada vez mais urgentes. Porém, tais ações ocorrem, em sua maioria, de forma isolada. Ações que buscam a integração entre educação ambiental e proteção e defesa civil não garantem a devida continuidade para a devida incorporação em currículos ou outras formas de inserção permanente. Nestas circunstâncias, é necessário que os projetos a serem executados sejam pensados de forma conjunta. As abordagens relacionadas à GRD devem ser contextualizadas com as noções sobre desenvolvimento sustentável de modo a integrar os diversos atores sociais com a melhor estratégia de aproximação ao se tratar do tema com as comunidades inseridas em áreas de risco. Ressalta-se que o sucesso das iniciativas de GRD depende da colaboração de todos os envolvidos no processo de redução de riscos 
de desastres, conforme prevê a PNPDEC. Esses envolvidos são a União, os Estados e Municípios, instituições não governamentais, iniciativa privada e sociedade.

A PNPDEC e a PNEA apresentam alto potencial de sinergia e de integração. Neste sentido, o presente estudo propõe a criação de diretrizes para definição de metodologias e mecanismos de integração da GRD na educação formal e não formal de forma permanente. Promover o ensino sobre os perigos naturais e os riscos associados possibilita o fortalecimento de medidas para minimizar os prejuízos da ocorrência de desastres e a autoproteção de cada indivíduo. Desse modo, a GRD se torna uma responsabilidade compartilhada entre o Poder Público e os cidadãos.

Os caminhos para se alcançar a GRD efetiva representam um grande desafio. Todavia, como demonstrado nesse estudo, muitos pesquisadores elevam a educação a um nível essencial para auxiliar nesta tarefa. Assim, partindo-se da análise de duas políticas públicas (PNPDEC e PNEA) que buscam contribuir para a promoção da educação para resiliência a desastres, suas interfaces foram discutidas com o intuito de superar a falta de integração. Por fim, diretrizes foram propostas a fim de viabilizar a sinergia e a integração entre PNPDEC e PNEA para atingir maior efetividade na GRD. Portanto, a consolidação dessa proposta pode contribuir para a redução dos riscos de desastres no Brasil, o que demonstra a necessidade e relevância deste debate.

\section{REFERÊNCIAS}

ALMEIDA, PEG de. A Política Nacional de Proteção e Defesa Civil: os desastres como problema político. In: Anais Seminário Internacional de Ciência Política [Internet]; 2015 set 911; Porto Alegre, Brasil. 2015 [cited in 2020 abr 10]. Available from: https://www.ufrgs.br/sicp.

AUSTRALIAN INSTITUTE FOR DISASTER RESILIENCE [Internet]. East Melbourne. [cited $2020 \mathrm{abr}$ 10]. What is disaster resilience education (DRE)? Education for young people. Available from: https://www.schools.aidr.org.au/disaster-resilience-education/what-is-disaster-resiliencieeducation/. 
AZEVEDO, LV, COSTA, DRTR; SANTOS, JR. Política Nacional de Educação Ambiental: Análise de sua aplicação em Projetos de Pesquisa e Extensão de Instituições Públicas de Ensino. Ciência e Natura [Internet]. 2017 [cited 2020 abr 10]39(3):701-722. Available from: http://dx.doi.org/10.5902/2179460x27105.

BACK, AG. Política Nacional de Proteção e Defesa Civil: Avanços e limites na prevenção de desastres. Revista Agenda Política. 2016 [cited 2020 abr 10]4(1):85-111, jan-abr/2016.

BARBIERI, JC; SILVA, D da. Desenvolvimento sustentável e educação ambiental: uma trajetória comum com muitos desafios. RAM, Rev. Adm. Mackenzie (Online), São Paulo, v. 12, n. 3, p. 51 82, 2011 jun. [cited in 2021 jan 15] Available from http://www.scielo.br/scielo.php?script=sci arttext\&pid=S1678-

69712011000300004\&lng=en\&nrm=iso

http://dx.doi.org/10.1590/S167869712011000300004.

BARBOSA, LC. Políticas Públicas de Educação Ambiental numa Sociedade de Risco. Tendências e Desafios no Brasil. In: IV Encontro Nacional da Anppas [Internet]; 2008 jun 4-6; Brasília, Brasil. 2008 [cited in 2020 abr 10].

BIRKLAND, T. Policy process theory and natural hazards. In: Oxford Research Encyclopedia of Natural Hazard Science. $2016 . \quad$ Available from: http://dx.doi.org/10.1093/acrefore/9780199389407.013.75.

BRANCO, EP; ROYER, MR; BRANCO, AB de G. A Abordagem da Educação Ambiental nos PCNs, nas DCNs e na BNCC. Nuances: estudos sobre Educação, [S.L.], v. 29, n. 1, p. 185-203, 20 dez. 2018. Nuances Estudos Sobre Educacao.

BRASIL. Lei $\mathbf{n}^{\circ} \mathbf{9 . 3 9 4}$ de 20 de dezembro de 1996. Estabelece as diretrizes e bases da educação nacional. Diário Oficial da União (Brasília), 1996 dez 20. Available from: http://www.planalto.gov.br/ccivil 03/LEIS/L9394.html .

BRASIL. Decreto $\mathbf{n}^{\circ} \mathbf{1 0 . 5 9 3}$ de 24 de dezembro de 2020. Dispõe sobre a organização e o funcionamento do Sistema Nacional de Proteção e Defesa Civil e do Conselho Nacional de Proteção e Defesa Civil e sobre o Plano Nacional de Proteção e Defesa Civil e o Sistema Nacional de Informações sobre Desastres. Diário Oficial da União (Brasília). 2020 dez 24. Available from: https://www.in.gov.br/en/web/dou/-/decreto-n-10.593-de-24-de-dezembro-de-2020296427343.

BRASIL. Lei n ${ }^{\circ}$ 12.608 DE 10 DE ABRIL DE 2012. Institui a Política Nacional de Proteção e Defesa Civil - PNPDEC; dispõe sobre o Sistema Nacional de Proteção e Defesa Civil - SINPDEC e o Conselho Nacional de Proteção e Defesa Civil - CONPDEC; autoriza a criação de sistema de informações e monitoramento de desastres; altera as Leis n 12.340 , de 1 de dezembro de 2010, 10.257, de 10 de julho de 2001, 6.766, de 19 de dezembro de 1979, 8.239, de 4 de outubro de 1991, e 9.394, de 20 de dezembro de 1996; e dá outras providências. Diário Oficial da União (Brasília). 2012 Abr 10. Available from: http://www.planalto.gov.br/ccivil 03/Ato20112014/2012/Lei/L12608.html. 
BRASIL. Lei $\mathbf{n}^{\circ} \mathbf{1 3 . 4 1 5}$ de $\mathbf{1 6}$ de fevereiro de 2017. Altera as Leis $n^{\circ}$ 9.394, de 20 de dezembro de 1996, que estabelece as diretrizes e bases da educação nacional, e 11.494, de 20 de junho 2007, que regulamenta o Fundo de Manutenção e Desenvolvimento da Educação Básica e de Valorização dos Profissionais da Educação, a Consolidação das Leis do Trabalho - CLT, aprovada pelo Decreto-Lei $n^{\circ} 5.452$, de 10 de maio de 1943, e o Decreto-Lei $n^{\circ} 236$, de 28 de fevereiro de 1967; revoga a Lei $n^{\circ} 11.161$, de 5 de agosto de 2005; e institui a Política de Fomento à Implementação de Escolas de Ensino Médio em Tempo Integral. Diário Oficial da União (Brasília), 2017 fev 16. Available from: http://www.planalto.gov.br/ccivil 03/ Ato20152018/2017/Lei/L13415.html .

BRASIL. Lei n 9.795 de 27 de abril de 1999. Dispõe sobre a educação ambiental, institui a Política Nacional de Educação Ambiental e dá outras providências. Diário Oficial da União (Brasília), 1999 abr 27. Available from: http://www.planalto.gov.br/ccivil 03/Leis/L9795.html .

BRASIL. Ministério da Educação, Conselho Nacional de Educação - CNE. Resolução n 02/2012 - Diretrizes Curriculares Nacionais para a Educação Ambiental. http://conferenciainfanto.mec.gov.br/images/pdf/diretrizes.pdf .

BRASIL. Ministério do Meio Ambiente. Educação Ambiental Por um Brasil Sustentável: ProNEA, Marcos Legais e Normativos. 5. ed. Brasília, DF: MMA, 2018.

CONSTITUIÇÃO DA REPÚBLICA FEDERATIVA DO BRASIL DE 5 DE OUTUBRO DE 1988. Diário Oficial da União (Brasília). 1988 out 5. Available from: http://www.planalto.gov.br/ccivil 03/Constituicao/ConstituicaoCompilado.html .

CUTTER, S. A Ciência da Vulnerabilidade: Modelos, Métodos e Indicadores. Trad. Por FERREIRA, V. Open Edition Jornauls. p. 59-59. 2011. Ed. Centro de Estudos Sociais da Universidade de Coimbra.

DA-SILVA-ROSA, T, MENDONÇA, MB, MONTEIRO, TG, SOUZA, RM de, LUCENA, R. A Educação Ambiental como estratégias para a redução de riscos socioambientais. Ambiente \& Sociedade [Internet]. 2015[cited 2020 abr 10];18(3):211-230. Available from: http://dx.doi.org/10.1590/1809-4422ASOC1099V1832015.

DULAC, VF, KOBIYAMA, M. Interfaces entre políticas relacionadas a estratégias para redução de riscos de desastres: recursos hídricos, proteção e defesa civil e saneamento. Revista de Gestão de Água da América Latina [Internet]. 2017[cited 2020 abr 10]14(e10). Available from: www.lume.ufrgs.br/handle/10183/184461.

ESTRATÉGIA ODS. O que são os ODS? [Internet]. [Cited 2020 abr 14]. Available from: http://www.estrategiaods.org.br/.

FACCHETTI, AR, SÉGUIN, E, KLIGERMAN, DC, COHEN, SC. Possíveis contribuições da integração das políticas públicas brasileiras à redução de desastres. Saúde debate [Internet] 2017. [Cited 2020 $a b r$ 10]41(2):39-49. Available from: 
http://www.scielo.br/scielo.php?script=sci arttext\&pid=S0103-

$11042017000600039 \&$ lng $=p t \& n r m=$ iso .

FURTADO, JD. Os caminhos da educação ambiental nos espaços formais de ensinoaprendizagem: qual o papel da Política Nacional de Educação Ambiental? Revista Eletrônica de Mestrado em Educação Ambiental [Internet]. 2009 [cited 2020 abr 10];22. Available from: https://periodicos.furg.br/remea/article/view/2830.

HERNANDES, PR. A Lei n 13.415 e as alterações na carga horária e no currículo do Ensino Médio. Ensaio: aval. pol. públ. Educ., Rio de Janeiro, v. 28, n. 108, p. 579-598, Sept. 2020. Available from http://www.scielo.br/scielo.php?script=sci arttext\&pid=S010440362020000300579\&lng=en\&nrm=iso . access on 15. Jan. 2021. E pub. June. 05, 2020. http://dx.doi.org/10.1590/s0104-40362020002802266.

KOBIYAMA, M; MONTEIRO, LR; MICHEL, GP. Aprender hidrologia para prevenção de desastres naturais. Florianópolis: UFSC/CTC/ENS/LabHidro, 2006b. 12p.(apostila), 2009.

LAYRARGUES, PP. Democracia e Arquitetura do Poder na Política Nacional de Educação Ambiental. Ambiente \& Educação Revista de Educação Ambiental [Internet]. 2009 [cited 2020 abr 10]14(1). Available from: https://periodicos.furg.br/ambeduc/article/view/1135/0 .

LEONARDI, ME. Políticas Públicas De Educação, Proteção E Defesa Civil No Paraná: Programa Brigada Escolar - Defesa Civil Na Escola. 2018. 121 f. Dissertação (Mestrado em Educação). Programa de Pós Graduação em Educação. Área de concentração: Sociedade, Estado e Educação, Linha de Pesquisa: Educação, políticas sociais e estado. Universidade Estadual do Oeste do Paraná - UNIOESTE, Cascavel, 2018.

MACHADO, JT. Educação ambiental: um estudo sobre a ambientalização do cotidiano escolar [thesis]. Piracicaba: Escola Superior de Agricultura "Luiz de Queiroz"; 2014. 245p.

MANYENA, SB. The concept of resilience revisited. Disasters, 30(4): 433-450.2006. Available from: https://doi.org/10.1111/j.0361-3666.2006.00331.x.

MARCHEZINI, V; AGUILAR, VM; TRAJBER, R. School vulnerability to disasters in Brazil. Territorium: Revista Portuguesa de riscos, prevenção e segurança, [s.l.], n. 25, p.161-177, 2018. Coimbra University Press. http://dx.doi.org/10.14195/1647-7723 25-2 13.

MÖNTERA, L, OTTO, K-H. The concept of disasters in Geography Education. Journal of Geography in Higher Education, 42(2), 205-219, 2018. Available from: https://doi.org/10.1080/03098265.2017.1339266.

MUTTARAK, R, LUTZ, W. Is education a key to reducing vulnerability to natural disasters and hence unavoidable climate change? Ecology and Society [Internet]. 2014 [cited 2020 abr 10];19(1):42. Available from: http://dx.doi.org/10.5751/ES-06476-190142 . 
NETO, JHCB. A Importância Do Desenvolvimento De Centros De Aprendizagem Em Redução Desastres (Drlc) E Sua Contribuição Para A Proteção E Defesa Civil Em Minas Gerais. 2017. 67 f. TCC (Graduação) - Curso de Curso de Formação de Oficiais da Academia de Bombeiros Militar de Minas Gerais, Academia de Bombeiros Militar, Belo Horizonte, 2017.

NOVICK, V, SOUZA, DBD. Políticas públicas de educação ambiental e a atuação dos conselhos de meio ambiente no Brasil: perspectivas e desafios. Ensaio: aval. pol. públ. Educ. [Internet]. 2010 [cited 2020 abr 10];18(69):711-736. Available from: http://www.scielo.br/scielo.php?script=sci arttext\&pid=S010440362010000400004\&lng=en\&nrm=iso .

OLIVEIRA, ET de; ROYER, MR. A Educação Ambiental no contexto da BNCC para o Ensino Médio. Interfaces da Educação, [S.L.], v. 10, n. 30, p. 57-78, 17 jul. 2020. Interfaces da Educação.

OLIVEIRA, FR; OURIQUES, JMA; CORREIA, LS. A Percepção de risco a partir do programa defesa civil na escola em Blumenau. Territorium, n. 25, p. 79-92, 23 mar. 2018. Coimbra University Press. Available from: https://impactum-journals.uc.pt/territorium/article/view/1647-7723 25$\underline{27 / 4845}$.

ORGANIZAÇÃO DAS NAÇÕES UNIDAS PARA EDUCAÇÃO, CIÊNCIA E CULTURA e FUNDO DAS NAÇÕES UNIDAS PARA INFÂNCIA. Redução de Riscos de Desastres nos Currículos Escolares. Estudo de Caso de Trinta Países [Internet]. Genebra: UNICEF e França: UNESCO; 2012 [Cited 2020 abr 10]. Available from: https://unesdoc.unesco.org/ark:/48223/pf0000220517.

PATRÍCIO, GR; FERNANDES, Jl; BRITO, LD; AZEVEDO, VCF; ANDRADE, TM. Gestão Ambiental Institucional: uma proposta de implantação do programa de gestão de resíduos gerados no IFPB: Campus João Pessoa. 2011. Available from: www.ibeas.org.br/congresso/Trabalhos2011/VII-019.pdf .

PETAL, MA, IZADKHAH, YO. Concept Note: Formal and Informal Education for Disaster Risk Reduction: A contribution from Risk RED for the International Conference on School Safety. [Internet]. 2008 [cited 2020 abr 10]. Available from: http://citeseerx.ist.psu.edu/viewdoc/summary?doi=10.1.1.371.284 .

RIBAS, LC, LEMOS SV, ANÁSTÁCIO, LBA. Bases para Políticas de Educação Ambiental no Brasil: Perspectiva Histórico-Cronológica. Pedagogia em Foco [Internet]. 2016 [cited 2020 abr 10];11(5):120-135. Available

from: http://revista.facfama.edu.br/index.php/PedF/article/view/174.

RIBEIRO, J; VIEIRA, R; TÔMIO, D. Análise da percepção do risco de desastres naturais por meio da expressão gráfica de estudantes do Projeto Defesa Civil na Escola. Desenvolvimento e Meio Ambiente, v. 42, p. 202-223, 24 dez. 2017. Universidade Federal do Paraná. http://dx.doi.org/10.5380/dma.v42i0.46271. Available from https://revistas.ufpr.br/made/article/view/46271. Acesso em: 02 ago. 2020. 
RODRIGUES, TA. Estratégia Internacional de Redução de Desastres. Revista Territorium [Internet] 2010 [cited $2020 \mathrm{abr}$ 10]17. Available from: https://digitalis.uc.pt/ptpt/artigo/estrat\%C3\%A9gia internacional de redu\%C3\%A7\%C3\%A30 de desastres.

SACHS, JD. A era do desenvolvimento sustentável. 2015 abr. Lisboa, Portugal.

SAITO, CH. As mútuas interfaces entre projetos e ações de educação ambiental e de gestão de recursos hídricos: subsídios para políticas de estado. Ambiente e sociedade [Internet]. 2011 [cited 2020 abr 10];14(1): 213-227, jun. 2011. Available from: http://www.scielo.br/scielo.php?script=sci arttext\&pid=S1414-

753X2011000100012\&lng=en\&nrm=iso .

SILVEIRA, R da; PANCERI, R. O Programa Defesa Civil Na Escola Como Prática Pedagógica Exitosa No Estado De Santa Catarina: uma ação no presente preparando o futuro das comunidades. In: PRANDEL, Jéssica Aparecida (Org.). Redução de Riscos e Desastres: métodos e práticas. Ponta Grossa (PR): Atena, 2019. cap. 13. p. 139-149.

SORRENTINO, M, TRAJBER, R, MENDONÇA, P, JUNIOR, LAF. Educação Ambiental como Política Pública. Educação e Pesquisa [Internet]. 2005 [cited 2020 abr 10];31(2):285-299. Available from: www.scielo.br/pdf/ep/v31n2/a10v31n2.pdf.

SULAIMAN, SN; JACOBI, PR. Os desafios e potencialidades da articulação entre educação ambiental e prevenção de desastres naturais no Brasil. In: 36 Reunião Nacional da ANPED [Internet]; 201329 set. - 02 out.; Goiás, Brasil. 2013 [cited 2020 abr 10]. Available from: www.anped.org.br/sites/default/files/gt22 3060 texto.pdf.

UCHÔA, RR. Avaliação do Programa "Brigada Escolar: A defesa civil na escola". 2013. Monografia (Especialização em Engenharia de Segurança do Trabalho) - Programa de PósGraduação em Engenharia Civil, Universidade Tecnológica Federal do Paraná. Curitiba, 2013.

UNISDR. [Cited 2020 abr 10]. Marco de Sendai para la Reducción del Riesgo de Desastres 2015-2030. Available from: https://www.preventionweb.net/sendai-framework/sendaiframework-for-drr .

UNISDR. Marco de Acción de Hyogo para 2005-2015. Aumento de la resiliencia de las naciones y las comunidades ante los desastres. Kobe (Japão): Conferencia mundial sobre la reducción de los desastres, 2015. 25p. Available from: www.eird.org/cdmah/contenido/hyogoframework-spanish.pdf.

UNISDR. [Cited $2020 \mathrm{abr}$ 10]. Worldwide Initiative for Safe Schools. Available from: https://www.unisdr.org/we/campaign/wiss .

VENDRUSCOLO, S, KOBIYAMA, M. Interfaces entre a Política Nacional de Recursos Hídricos e a Política Nacional de Defesa Civil, com relação aos desastres hidrológicos, no Brasil. In: Jornadas Internacionales sobre Gestión Del Riesgo de Inundaciones y Deslizamientos de Laderas 
[Internet]; 2007; São Carlos, Brasil. 2007 [cited 2020 abr 10]. Available from: www.labhidro.ufsc.br/Artigos/prohimet0507.pdf .

VIANA, RG, SAMPAIO, DR, ARAGÃO, RF. Reflexões sobre a política nacional de educação ambiental como ferramenta de preservação do meio ambiente [Internet]. Jus Navigandi; 2016 set [cited 2020 abr 10]. Available from: https://jus.com.br/artigos/52317/reflexoes-sobrea-politica-nacional-de-educacao-ambiental-como-ferramenta-de-preservacao-do-meioambiente.

VIEIRA, R, MÜLLER, GCK, MARCHI, TL. Projeto “Defesa Civil na Escola”: uma avaliação desta ação na educação ambiental para gestão de riscos de desastres naturais em Blumenau/SC. Revista de Estudos Ambientais [Internet]. 2017 nov 20 [cited 2020 abr 10];19(1):44-60. Available from: http://dx.doi.org/10.7867/1983-1501.2017v19n1p44-60.

WEICHSELGARTNER, J, PIGEON, P. The role of knowledge in disaster risk reduction. International Journal of Disaster Risk Science [Internet]. 2015 nov [cited 2020 abr 10];6(2):107-116. Available from: http://dx.doi.org/10.1007/s13753-015-0052-7.

WISNER, B, GAILLARD, JC; KELMAN, I. 13 Dec 2011, Framing Disaster from: The Routledge Handbook of Hazards and Disaster Risk Reduction Routledge Available from: https://www.routledgehandbooks.com/doi/10.4324/9780203844236.ch3.

\section{Contribuições de autoria}

\section{1 - Amanda Regina Coutinho da Silva}

Mestre em Desastres Naturais

https://orcid.org/0000-0002-3232-3715 - amandarcoutinho@hotmail.com

Contribuição: Conceituação, Investigação, Escrita - primeira redação, revisão e edição

\section{2 - Masato Kobiyama}

Professor do Instituto de Pesquisas Hidráulicas, Doutor em Engenharia Florestal https://orcid.org/0000-0003-0615-9867 - masato.kobiyama@ufrgs.br Contribuição: Conceituação e Escrita - revisão e edição

\section{3 - Franciele Maria Vanelli}

Mestre e Doutoranda em Recursos Hídricos e Saneamento Ambiental https://orcid.org/0000-0001-8763-5786 -franciele.vanelli@ufrgs.br Contribuição: Escrita - revisão e edição

\section{Como citar este artigo}

SILVA, A. R. C.; KOBIYAMA, M.; VANELLI; F. M.. Interfaces entre a política nacional de proteção e defesa civil e a política nacional de educação ambiental. Ciência e Natura, Santa Maria, v. 43, e60, p. 1-32, 2021. Disponível em: https://doi.org/10.5902/2179460X43612. 